\section{PENYULUHAN DAN PENDAMPINGAN PROGRAM PERILAKU HIDUP BERSIH DAN SEHAT DI KELURAHAN BANTEN KECAMATAN KASEMEN}

\author{
Budi Hasanah $^{1}$, Adi Suharyanto ${ }^{2}$, Dita Budiarti ${ }^{3}$, \\ Yuke Winaldha Fiscaranie ${ }^{4}$
}

Prodi Administrasi Publik Fakultas Ilmu Sosial, Ilmu Politik dan Ilmu Hukum Universitas Serang Raya

*Corresponding author

Email : budihasanah@gmail.com

\section{Abstraksi}

Program Perilaku Hidup Bersih dan Sehat (PHBS) yang berlaku di Kelurahan Banten Kecamatan Kasemen kurang berjalan dengan optimal karena multifaktoral. Mulai dari masyarakat yang tidak paham apa itu PHBS sampai pada sulitnya mengaplikasikan perilaku hidup bersih dan sehat salah satunya karena masyarakat sudah terbiasa menerapkan pola hidup yang tidak bersih dan sehat. Padahal program ini merupakan program pemerintah yang betujuan untuk meningkatkan kualitas kesehatan bagi seseorang, keluarga atau masyarakat. Untuk mendukung penyuluhan dan pembinaan diperlukan proses edukasi kepada masyarakat yang mewakili keluarganya masing-masing dalam upaya peningkatan kualitas kesehatan masyarakat melalui penyuluhan dan pendampingan. Setelah dilakukannnya penyuluhan kemudian adanya pendampingan Pemberian Makanan Tambahan (PMT) bagi anak yang mengidap gizi kurang dan/atau buruk dimana penyakit ini merupakan salah satu dampak dari pola hidup yang tidak sesuai dengan pedoman hidup bersih dan sehat. Kegiatan pendampingan PMT ini dilakukan karena jumlah anak yang mengidap gizi kurang dan/atau buruk sudah masuk pada zona merah. Kegiatan ini dilaksanakan di Kantor Kelurahan Banten dimana mitra sebagai peserta kegiatan ini adalah warga Pekapuran RW 01 dengan metode transfer informasi dan pendampingan. Hasil pengabdian ini diharapkan mampu memberikan gambaran dan menjadi stimulus bagi masyarakat akan pentingnya kesehatan khususnya warga di lingkungan Pekapuran Kelurahan Banten.

Kata Kunci : Penyuluhan , Pendampingan, Program PHBS

\section{Abstract}

Perilaku Hidup Bersih dan Sehat Program (PHBS) was also apply in Kelurahan Banten, Kasemen it's not runing well because of multifactoral reason. Starting from people who did not understand what PHBS was and the difficulty of applying the clean and healthy life. It was happened because people was accustomed to apply unhealthy life. This progam was the government program to improve the health quality for person, family and society. The scope of PHBD was in the family environment. To support the counseling and coaching, an education process was needed for people who represent their families in order to improve the quality public health through counseling and mentoring. After counseling, there was accompaniment of the supplementory food supply for children who suffered malnutrition, which the disease was on of the effect of lifestyle that was not in accordance with the guideline of clean and healthy life. The supplementory food supply was done because the number of children suffering from mainutrition was in the red zone. The program was carried out in the Kelurahan Banten Office and the partner of this program was people in the Pekapuran RW 01. The method were information transfer method and assistance. The result if this service were expected to be abble to provide an overwiew and become a stimulus for society about the importance of health especially for people in Pekapuran Kelurahan Banten.

Key Words : counseling, Assistance, PHBS Program 


\section{PENDAHULUAN}

Program Perilaku Hidup Bersih dan Sehat atau atau disingkat dengan Program PHBS merupakan salah satu program pemerintah yang bukan tanpa alasan dan tanpa tujuan yang tidak urgent. Artinya, masyarakat Indonesia masih jauh dari pola hidup bersih dan sehat diantaranya adanya masyarakat yang tinggal di Kelurahan Banten Kecamatan Kasemen Kota Serang. Padahal hidup sehat adalah hak setiap orang dimana hal ini terdapat di dalam konstitusi (UUD 45) bahwa setiap orang berhak hidup sejahtera lahir dan batin, bertempat tinggal dan mendapatkan lingkungan hidup yang baik dan sehat serta berhak memperolah pelayanan kesehatan.

Kelurahan Banten memiliki total jumlah penduduk sebanyak 14.687 orang, diantaranya sebanyak 7.580 laki-laki dan 7.107 perempuan dan secara geografis kelurahan ini adalah pantai dimana masih banyak penduduknya yang tidak tamat sekolah wajib belajar 9 (sembilan) tahun yaitu sebanyak 4.862 Kepala keluarga. Sedangkan Kepala Keluarga yang tamat SD-SLTP yaitu sebanyak 12.987, Tamat SLTA 2.978 dan tamat AK/PT 786 kepala keluarga. Lebih jelasnya dapat dilihat pada gambar berikut.

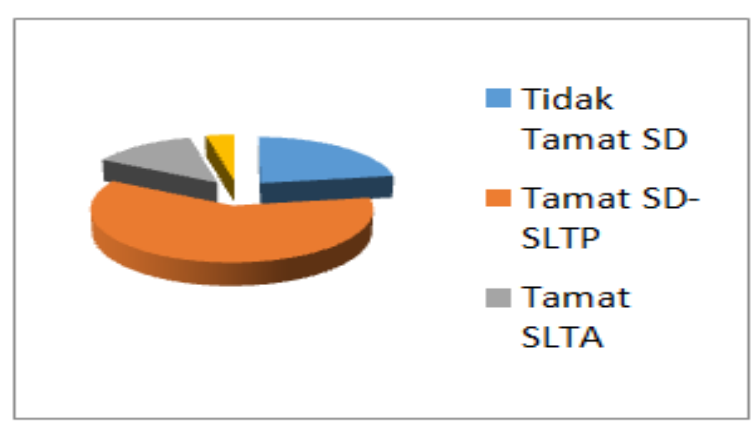

Gambar 1. Jumlah Kepala Keluarga Menurut Status Pendidikan di Kelurahan Banten Tahun 2014, Sumber: Badan Pusat Statisktik Kota Serang Kecamatan kasemen dalam Angka Tahun 2017

Kelurahan Banten masuk ke dalam kawasan Banten Lama yang memiliki peninggalan sejarah yang terkenal baik nasional maupun internasional. Kelurahan Banten memiliki potensi wilayah dimana dalam pembatasan wilayah terdapat 4 (empat) letak batas di Kelurahan Banten ini yaitu sebelah utara dimana terdapat Kelurahan Laut Jawa, Sebelah selatan terdapat Kelurahan Kasunyatan, di sebelah timur terdapat Desa/Keluarahan Margayu yang berada di Sawah Luhur kemudian di sebelah barat terdapat Kelurahan Pemengkang di Kecamatan Kramat.

Kelurahan Banten memiliki beberapa kampung salah satunya adalah Pekapuran. Dalam pelaksanaan kegiatan ini, warga yang terlibat sebagai mitra kegiatan adalah warga 
Kampung Pekapuran yang merupakan RW 01 dimana RW ini terdiri 4 (empat) RT. Daerah ini termasuk ke dalam zona merah yang artinya daerah ini masih banyak masalah sehingga perlu adanya pemberdayaan. Pemberdayaan mengandung arti perbaikan mutu hidup atau kesejahteraan setiap individu dan masyarakat salah satunya perbaikan kesejahteraan sosial yaitu bidang kesehatan (Mardikanto dan Soebiato, 2004:28). Kegiatan pemberdayaan disini bukan tanpa tujuan, artinya dalam pemberdayaan yang dilaksanakan di Kantor Kelurahan Banten setidaknya terdapat beberapa tujuan yang didapat meliputi beragam upaya perbaikan sebagai berikut.

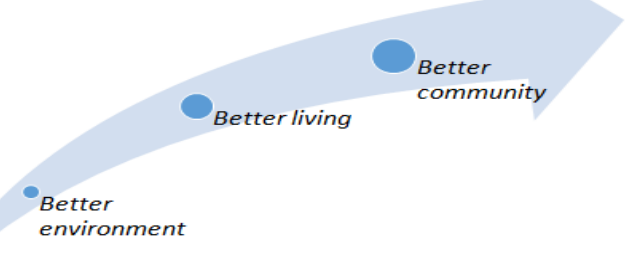

Gambar 2. Tujuan Pemberdayaan Mayarakat. Sumber: Thresia, Aprillia, dkk. (2014:153)

Masyarakat di Kelurahan Banten dalam kegiatan ini khususnya di Kampung Pekapuran masih kurang memiliki kesadaran mengenai pentingnya hidup bersih dan sehat, hal ini dibuktikan dengan masih banyaknya masyarakat yang membuang sampah tidak pada tempatnya seperti di bantaran sungai dan di bantaran rel kereta api dan kondisi air juga masih sangat kotor. Selain itu, masyarakat Kampung Pekapuran juga banyak yang membuang tinjanya di sekitar rel kereta api dan di sungai. Berdasar hal ini memperlihatkan bahwa kesadaraan masyarakat terhadap kesehatan masih rendah, ditambah lagi terdapat beberapa masyarakat yang menggunakan barang terlarang seperti narkoba, sabu dan lainlain. Selain permasalahan diatas ada pula permasalahan mengenai gizi buruk sebanyak 13 (tiga belas) anak di Kelurahan Banten. Oleh karena itu pentingnya kegiatan penyuluhan disini. Peran penyuluh dalam penyelenggaraan penyuluhan lebih mengarah pada perubahan berencana. Perubahan berencana mengimplikasikan pentingnya pendidik atau penyuluh dalam pengembangan program penyuluhan (Huda, Nurul dan Harijati, Sri, 2016)

Selain kegiatan penyuluhan, dilakukan juga kegiatan pendampingan dalam pemberian makanan tambahan bagi anak yang gizi kurang atau buruk. Pemberian Makanan Tambahan (PMT) adalah program intervensi bagi balita yang menderita gizi kurang atau buruk dimana tujuannya adalah untuk meningkatkan status gizi anak serta mencukupi kebutuhan zat gizi anak agar tercapainya status gizi dan kondisi gizi yang baik sesuai dengan usia anak. program ini akan dilanjutkan ke depan setiap 
seminggu sekali oleh aparatur Kelurahan Banten di Kantor Kelurahan Banten.

\section{METODE PELAKSANAAN}

Pada kegiatan ini menggunakan metode penyuluhan mengenai Program Hidup Bersih dan Sehat (PHBS). Peran penyuluh yaitu menyampaikan inovasi dan memengaruhi proses pengabilan keputusan yang dilakukan oleh penerima manfaatnya. Selain itu, penyuluh juga sebagai jembatan penghubung antara pemerintah atau lembaga pemberdayaan masyarakat yang diwakili dengan masyarakatnya, baik dalam hal menyampaikan inovasi atau kebijakan-kebijakan yang harus diterima dan dilaksanakan oleh masyarakat, maupun untuk menyampaikan umpan balik atau tanggapan masyarakat kepada pemerintah atau lembaga pemberdayaan yang bersangkutan (Mardikanto dan Soebiato, 2004:140)

Selain kegiatan penyuluhan, dilakukan juga pendampingan PMT (Pembagian Makanan Tambahan) bagi anak yang gizi kurang atau buruk. Pada kegiatan pengabdian ini bermitra dengan warga di Lingkungan Pekapuran RW 01 yang masuk ke dalam Kelurahan Banten dimana peserta yang hadir adalah peserta yang berstatus sudah berkeluarga karena salah satu ruang lingkup dari target program PHBS ini adalah keluarga.
Sedangkan pada kegiatan pendampingan PMT yang menjadi peserta kegiatan adalah anakanak yang kurang atau gizi buruk. Lokasi dilakukannya penyuluhan dan pendampingan ini yaitu di Kantor Kelurahan Banten. Kegiatan ini juga melibatkan perwakilan dari pihak puskesmas bagian Kesehatan Masyarakat (Kesmas) Kecamatan Kasemen.

Tahapan pelaksanaan pada kegiatan ini yaitu, 1) transfer informasi mengenai Perilaku Hidup Bersih dan Sehat kepada warga Pekapuran yang hadir sebagai peserta kegiatan pengabdian. Tujuan kegiatan ini adalah peserta pada penyuluhan mengetahui Program Perilaku Hidup Bersih dan Sehat. Kegiatan ini dilaksanakan dengan cara penyampaian materi dan adanya diskusi tentang latar belakang dari kegiatan ini, pengertian PHBS, pentingnya pola pikir sehat kepada masyarakat, tujuan dari upaya PHBS, dasar hukum bahwa kesehatan merupakan hak setiap warga, faktor-faktor yang memengaruhi derajat kesehatan, manfaat PHBS. Penyuluhan ini disampaikan oleh dosen, perwakilan dari mahasiswa dan dari pihak Puskesmas Kasemen bagian Kesejahteraan Masyaraat (Kesmas); 2) pendampingan Pembagian Makanan Tambahan (PMT) untuk anak gizi kurang atau buruk dimana hal ini menjadi salah satu dampak warga tidak peduli terhadap pola hidup bersih dan sehat. 


\section{HASIL DAN PEMBAHASAN}

Kegiatan penyuluhan program PHBS dan pendampingan PMT ini dilaksanakan di kantor Kelurahan Banten, Kecamatan Kasemen, Kota Serang. Kegiatan ini dihadiri oleh 64 peserta yang didominasi oleh bapakbapak sedangkan pada kegiatan penyuluhan dan 21 peserta pada pendampingan PMT. Pada kegiatan ini yang menjadi mitra yaitu kelompok ibu-ibu rumah tangga, perwakilan RW dan RT, Kader Posyandu serta dari pihak Puskesmas Kasemen yaitu bagian Kesmas atau Kesejahteraan Masyarakat.

Peserta yang hadir merupakan mitra kegiatan pengabdian masyarakat sangat senang mengikuti kegiatan ini. hal ini terlihat dari banyaknya peserta yang hadir dan aktifnya peserta pada kegiatan ini dengan mengajukan berbagai pertanyaan dan pernyataan. Seperti yang dipaparkan oleh salah satu peserta bahwa memang ada beberapa rumah yang masih belum memiliki MCK dan belum layaknya MCK yang dimiliki oleh beberapa rumah warga sehingga masyarakat yang melakukan kegiatan mandi, mencuci, buang air kecil dan besar di bantaran sungai dan ada pula yang di pemandian umum. Selain itu, sulitnya warga untuk berhenti merokok atau bahkan tidak merokok di sembarang tempat contohnya di dalam rumah karena hal ini sudah menjadi kebiasaan warga karena memang mata pencaharian warga sebagian besar yang hadir pada kegiatan ini adalah nelayan. Menurut warga, nelayan disini identik dengan merokok karena suhu yang dingin pada saat mencari ikan dan dengan cara merokok, mereka dapat menstabilkan suhu yang dingin tersebut menjadi lebih hangat.

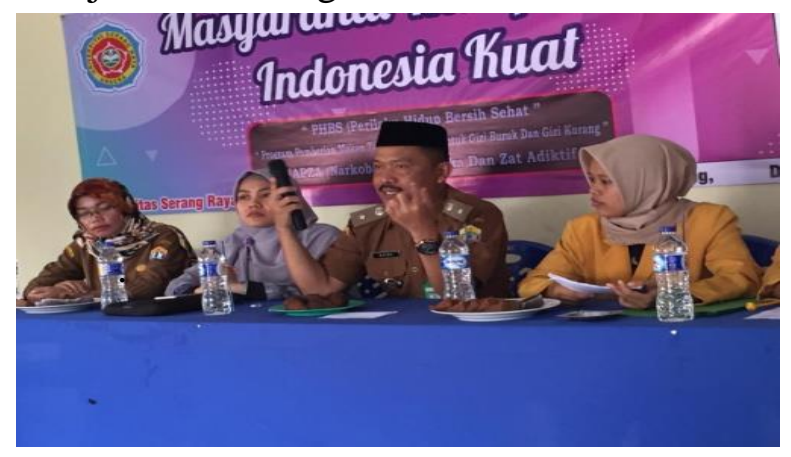

Gambar 3. Sambutan Kepala Lurah Banten dilanjut penyuluhan oleh tim pengabdian, Sumber: Tim Pengabdian, 2019

Adapun anak yang mengidap giji kurang atau buruk disini masuk pada zona merah. Artinya jumlahnya tidak sedikit yaitu sebanyak 13 anak. Hal ini memang menurut Kepala BPS Kota Serang (Kabar Banten, 2017), basis data terpadu yaitu program perlindungan sosial yang dikelola oleh Tim nasional Percepatan Penanggulangan Kemiskinan (TNP2K), untuk tahun 2015 dari indikator 40 persenlebih ada sekitar 10.325 rumah tangga miskin di Kecamatan Kasemen dan ini merupakan jumlah yang lebih banyak dibandung dengan kecamatan lainnya di Kota Serang. Artinya, Kecamatan Kasemen adalah Kecamatan yang termiskin di Kota Serang, 
oleh karena itu taraf hidupnya masih rendah salah satunya untuk mendapkan makanan yang bergizi khususnya bagi anak-anak.

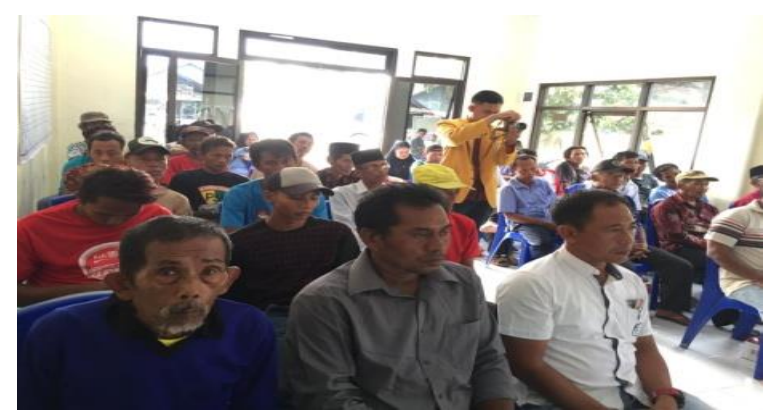

Gambar 4. Antusias warga yang hadir dalam kegiatan di Kantor kelurahan Banten

Sebelum kegiatan pengabdian ini dilaksanakan, tim pengabdian membuat kuisioner yang disebar ke peserta kegiatan pada saat sebelum dan setelah kegiatan berlangsung. Hasil kegiatan pengabdian ini dapat dilihat pada gambar berikut.

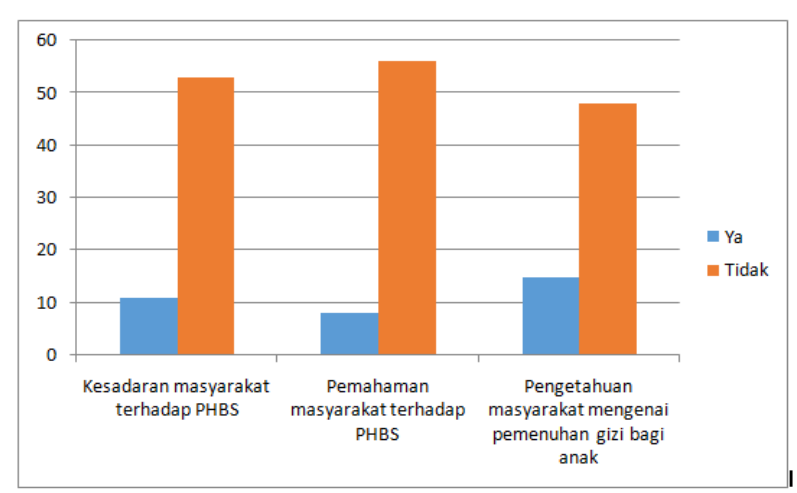

Gambar 5. Hasil kuisioner sebelum kegiatan penyuluhan, Sumber : Data Primer, 2019

Berdasar hasil kuisioner menunjukan bahwa sekitar $82,8 \%$ warga yang hadir tidak memiliki kesadaran akan pentingnya perilaku hidup bersih dan sehat dan sekitar 90,6\% peserta yang hadir belum memahami perilaku hidup bersih dan sehat serta sekitar 76,5\% masyarakat yang hadir tidak mengetahui apa saja makanan untuk memenuhi gizi yang baik bagi anak-anak.

Setelah kegiatan ini dilaksanakan dengan baik, hal ini mengalami peningkatan kesadaran dan pengetahuan peserta tentang pentingnya hidup bersih dan sehat. Sekitar sebanyak 95,3\% peserta yang hadir sadar akan pentingnya pola hidup bersih dan sehat dan sekitar $96,8 \%$ peserta yang hadir paham akan pentingnya kesehatan dan mengetahui makanan apa saja untuk memenuhui gizi pada saat selama anak masih di dalam kandungan sampai pada kelahiran dan masuk pada usia anak. lebih jelasnya dapat dilihat pada gambar berikut.

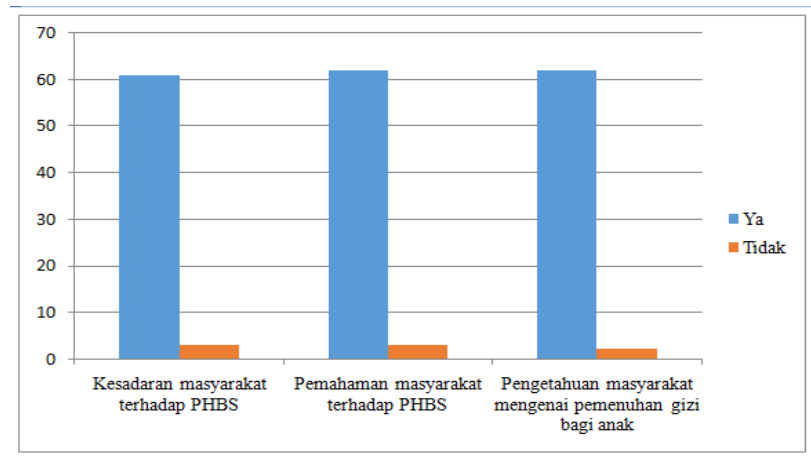

Gambar 6. Hasil kuisioner sebelum kegiatan penyuluhan, Sumber: Data Primer, 2019

Selain itu, terjadi pula derajat perubahan perilaku masyarakat untuk dapat memenuhui gizi yang baik bagi anak. Hal ini terlihat dari total anak yang gizi kurang atau 
buruk sebanyak 13 anak, 92,3\% anak yang dibawa oleh ibunya mengikuti kegiatan Pembagian Makanan Tambahan (PMT) untuk anak yang masuk pada kategori kurang atau gizi buruk. Walaupun dalam pelaksanaannya secara teknis tidak mudah karena ibu-ibu sulit datang pada kegiatan ini seperti kegiatan sebelumnya yang dilaksanakan oleh Kelurahan Banten. Hal yang sama terjadi pada kegiatan PMT ini dimana ibu-ibu harus dijemput setiap rumah oleh tim pengabdian untuk hadir kegiatan PMT di Kantor Kelurahan Banten. Jika tidak dijemput maka ibu-ibu enggan untuk hadir karena berbagai alasan, seperti pekerjaan rumah belum selesai dan alasan lainnya yang kemungkinan besar mereka tidak hadir. Dapat diambil simpulan bahwa harus ada paksaan terlebih dahulu bagi ibu-ibu untuk dapat hadir dengan membawa anak mereka yang mengidap penyakit gizi buruk dan gizi kurang. Kegiatan ini dilakukan seminggu sekali yaitu setiap Hari jum'at selama 3 (tiga) bulan kedepan. Tim pengabdian melakukan kerjasama dalam kegiatan ini yaitu pihak Kelurahan Banten, Puskesmas Kasemen serta warga setempat. Kegiatan pendampingan perdana yaitu pemberian biskuit dan susu kepada anak-anak penderita gizi buruk dan gizi kurang. Untuk kegiatan selanjutnya yang berlangsung setiap seminggu sekali sampai pada 3 (tiga) bulan kedepan ini menjadi program Keluarahan
Banten sesuai kesepatakan antara tim pengabdian dan Kelurahan Banten. Pihak Kelurahan Banten akan menyediakan makanan 4 sehat 5 sempurna bagi anak penderita gizi buuk dan gizi kurang an diharapkan anak yang termasuk pada kategori tersebut dapat mengikuti secara keseluruhan tanpa terkecuali. Berikut gambar yang memperlihatkan kegiatan pendampingan PMT di Kantor Kelurahan Banten.
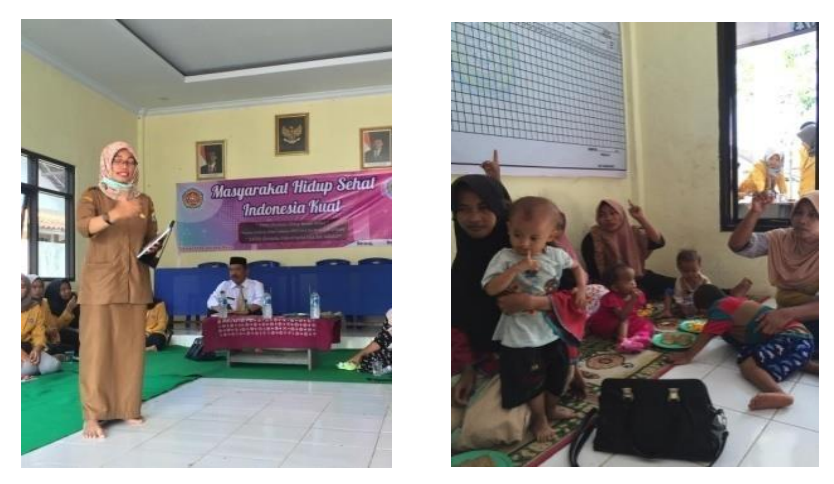

Gambar 7 dan 8.

Pendampingan yang dihadiri pula dari pihak Puskesmas Kasemen bagian Kesehatan Masyarakat dan ibu-ibu yang hadir bersama anaknya yang mengindap gizi kurang dan gizi buruk yang akan menerima PMT, Sumber : Tim Pengabdian, 2019

\section{PENUTUP}

Penutup pada kegiatan pengabdian ini adalah berupa simpulan yaitu adanya peningkatan pemahaman dan dibuatkannya komitmen warga untuk menjaga dirinya dan keluarganya agar selalu mejalankan perilaku hidup bersih dan sehat sehingga warga Pekapuran menjadi warga yang sejahtera dari 
aspek kesehatan. Selain itu, warga menjadi tahu makanan apa saja untuk dapat meningkatkan gizi bagi anak-anak mereka sehingga asupan gizi selanjutnya dapat terkontrol dengan baik oleh orang tuanya yang sesekali akan dipantau oleh Kepala Lurah Banten.

\section{REFERENSI}

Huda, Nurul dan Harijati, Sri. 2016. Peran Penyuluh dalam Pemberdayaan Masyarakat Pertanian Perkotaan. Peran MST dalam Mendukung urban Lifstyle yang Berkualitas. Halaman 205-222

Mardikanto, Totok dan Soebiato, Poerwoko. 2004. Permberdayaan Masyarakat dalam Perspektif Kebijakan Publik. Bandung : Alfabeta

Theresia, Aprillia, dkk. 2014. Pembangunan Berbasis Masyarakat. Bandung: Alfabeta

\section{Dokumen}

Badan Pusat Statistik Kota Serang Kecamatan kasemen dalam Angka Tahun 2017

\section{Internet}

Kabar Banten. 26 November 2017. Warga Miskin Numpuk di Kaasemen. http://www.kabar.banten.com/warga-miskinnumpuk-di-kasemen/ diakses pada 2 Februari 2019 